\title{
SocArXiv
}

Preprint : February 19, 2021

10.31235/osf.io/m7ah4

\section{Two worlds of online labour markets: Exploring segmentation using finite mixture models and a network of skill co-occurrence}

\author{
Martin Lukac \\ Department of Methodology \\ London School of Economics and Political Science \\ Current version: https://osf.io/preprints/socarxiv/m7ah4
}

\begin{abstract}
Technological innovations have enabled the emergence of online labour market platforms, empowering individuals to penetrate the world of traditional offshoring and challenging localised labour market dynamics. A great number of workers thrive at online platforms and embrace these tools to find customers for their businesses, to counterbalance market fluctuations, and earn wages above the local average. However, online labour market workers are also known to suffer numerous drawbacks, such as precarious working conditions, unpaid work, and severe fragmentation of jobs into tasks that limit skill use and development. Yet, our understanding of what causes this divergence in experiences is limited. Adopting propositions from the labour market segmentation literature, I show that, similarly to offline markets, online labour markets are composed of structurally delimited segments with different social processes governing the allocation of work. Using unsupervised clustering techniques from network science, I show that the clustered skill topology constrains mobility between segments in online platforms. I also show that this segmentation explains large differences in the earnings potential of individual workers. Together, these results provide a new explanation for the persistence of diversified experiences in online labour markets and inform strategies for future research of online platforms as highly segmented labour markets.
\end{abstract}

Keywords: online labour markets, labour market segmentation, platform economy, finite mixture models, network analysis, clustering. 


\section{Introduction}

The advent of information and communication technologies redefined the notion of a global labour market. Online labour markets (OLM) are online platforms that match supply and demand for digitally deliverable services (e.g. graphic design, software development, translations, etc.). OLM platforms - such as Fiverr, Freelancer, or Upwork - have witnessed unprecedented growth in the recent years, as they made it possible for one-person micro-providers to penetrate the world of traditional offshoring by allowing anyone with a computer and Internet connection to perform work online (Lehdonvirta et al., 2018). Research, however, shows that online workers often face precarious working conditions (De Stefano, 2016): they are insufficiently covered by social protections (see Emmenegger et al., 2012), their employment is prone to market volatility that induces inability to plan ahead (Eurofound, 2017), and often face long working hours or stressful deadlines that can lead to burnout (Wood et al., 2018). Nevertheless, evidence of workers who are able to thrive in the online environment or use these tools to find more customers appear at an equally fast pace and cannot be ignored (for example, see Lehdonvirta et al., 2015). Work at OLM platforms is highly diverse and not all work online ought to be labelled as poor quality (Eurofound, 2019). I argue that because of this diversity, OLMs do not produce unified experiences and suggest that dominant interpretations of labour in the digital world are insufficient.

Classical economic approaches tended to view labour markets as spot markets for labour in which the market forces of supply and demand lead to optimal work allocation and pricing. In opposition to this conception, theories of dual labour market and segmented labour markets maintain that jobs can be roughly divided into two groups: those with low wages, bad working conditions, unstable employment and little opportunity for advancement - a secondary labour market; and those with relatively high wages, good working conditions and opportunities for advancement into higher paying jobs - a primary labour market (Doeringer \& Piore, 1971). Analogously to the classical economics view, OLMs tend to be presented as spot markets for labour and are expected to obey the stylised rules of supply and demand. The expectation is that owing to the ease of access to these labour markets and available information on previous exchanges at the platform, employers and employees engage in almost perfectly competitive market dynamics. Available research does not support this view and shows that OLMs are likely to suffer from information asymmetries (Autor, 2001; Horton, 2010), cumulative Matthew effects (Pallais, 2014), and entry barriers for platform newcomers (Lukac \& Grow, 2020; Pelletier \& Thomas, 2018). Recent investigation uncover more and more evidence that the platform economy contributes to labour market segmentation tendencies (Ilsøe et al., 2021).

Following this strand of evidence, I engage with both approaches and elaborate on the microand macro-mechanisms that give rise to segmented labour market outcomes at online platforms. I investigate whether OLM platforms are also divided into self-contained segments with different rules of work allocation and working conditions. This paper formulates three central propositions of online labour market segmentation: First, the presence of distinct labour markets with different social processes of work allocation. Second, the lack of mobility between the labour market segments. Third, the difference in conditions of work in different labour market segments. Despite significant differences between the two approaches to labour markets - the classical versus the segmented - this paper shows how both, the micro-mechanisms of human capital and transaction costs as well as macro-mechanisms of platform authoritarianism and 
bargaining power, align on producing segmented labour market outcomes online.

To test these propositions, I use two modelling techniques. First, I use finite mixtures of regression models to test for presence of distinct labour market segments with different processes of work allocation. Labour market segments are modelled as membership in unobserved classes, which are inferred from the relationships between the variables. Second, I use network analysis approach to visualise and analyse skill co-occurrence. This is done in order to inquire into existence of skill clusters, which are expected to strongly correlate with segment membership and to investigate mobility between segments. Finally, I use the inferred segment membership from the finite mixture model to investigate differentiation between the segments in terms of work quality.

Results provide considerable support for the view of two distinct segments: First, a pricedriven segment, predicted by transaction costs economics theory, where work is assigned to workers with the lowest reservation wages and comprises mostly low-skill work. Second, a reputation-driven segment, sought by employers for workers' high value-added abilities, where work is assigned to the workers with highest reputation regardless of their price. These segments are highly correlated to skills, hence incoming worker's skill-set is a strong predictor of finding work in either of the two segments (McDonald et al., 2019). Results suggest that there is indeed limited mobility between the segments as workers who found work in one segment seldom find work in the other later on. Moreover, due to jobs being fragmented into individual tasks (Rubery et al., 2009), employees are unlikely to upgrade their skills by working at OLMs (Standing, 2011). Consequently, employees tend to stick to a limited number of skills that they perform online and thus remain trapped in their respective segment. These structural barriers are predicted by platform authoritarianism literature (Ajunwa, 2018); as the platform restricts the actions available to workers on one side while offering new opportunities to employers on the other. The freelancers must engage with the platform on its own terms or lose the opportunity to work (Ajunwa \& Greene, 2019). Finally, OLM segments are differentiated strongly by the average revenue per project that workers earn, as the reputation-driven segment earns substantially more than the price-driven segment. The advantage of higher earnings compounds over time and might lead to significant Matthew effects (Merton, 1968) in the long run. Workers in the reputation-driven segment have more autonomy to decide price of their work and also feel remunerated more fairly than the price-driven segment. Surprisingly, segments are not differentiated in terms of competition that freelancers face in each segment.

In what follows, I first discuss the theoretical background of online labour market segmentation. Second, I present the data used for the empirical tests of proposed hypotheses and the methods. Third, I present the results obtained from the analysis, followed by a discussion of their implications. I end with conclusions and implications for future research.

\section{Theoretical background}

Information and communication technologies improved matching between employees and employers, made delivery of services online possible, and made employment demand less dependent on local labour market conditions (see Autor, 2001). As a result, offshoring and outsourcing became not only possible, but efficient ways for firms to access remote labour pools and became a regular practice for firms worldwide. In the last decade, however, these "traditional" offshoring modes were challenged by new forms of offshoring, such as one-person 
micro-providers - individuals offering their services at online labour marketplace platforms, giving rise to a global platform economy (Lehdonvirta et al., 2018).

Platforms investigated in this paper differ from location- or app-based platforms (e.g. UBER or Deliveroo), which assign location specific transportation and delivery tasks, or microtasking (e.g. Amazon MTurk) that distributes low-skilled tasks to large crowds. OLMs (Horton, 2010) that this paper investigates are freelance marketplaces, where digital labour is distributed via a web-based platform and allocated to an individual freelancer in an auction-like environment (examples include Fiverr, Freelancer, or Upwork). Projects advertised at these platforms range from low-skill (e.g. data entry, typing, or clerical work) to high-skill labour (e.g. software development, graphic design, etc.). Exchanges are typically initiated by an employer creating a public project with a description of the requested service and specifying their budget. Freelancers can subsequently place bids (i.e. price proposals) on the project in an auction (either seeing or not seeing bids of other freelancers), with a short message to the employer and expected time of delivery of the service. The employer can choose (or decide not to choose) a freelancer at any moment. After the freelancer accepts the employer's proposal, the project commences. Payments for work can be made either during the project, based on the number of hours worked, or at the end as a lump sum when the project is delivered. Once the freelancer delivers the project, both parties are asked to leave public feedback about their exchange.

Evaluation and selection of workers and matching with prospective employers online is typically based on very limited information about the counterpart (Gandini, 2016). A common problem that arises in the OLM setting is one of information asymmetry. Freelancers face various risks when accepting employment online (Benson et al., 2019): their employers may opportunistically change agreed upon conditions of employment, violate inherent expectations and norms of online work, and even withhold salary for finished work. These frictions are exacerbated even more due to issues of geographical and cultural distance or absence of global legal protections against fraud (Gandini, 2016; Kässi \& Lehdonvirta, 2018). The asymmetry is disproportional for workers, who are forced to consent to the information asymmetries and command structures embedded in the workplace, due to the need to afford basic necessities (Anderson, 2017). However, just as freelancers, employers face a risk when hiring freelancers online: risk of a low-quality service, delays in project delivery, or plagiarising of intellectual property assigned to a worker. Information asymmetry is present, because the freelancer has the information about their innate ability, work quality, and intentions, while the employers do not. Consequently, evaluation and selection of applicants becomes a relatively complex matter. In profiles, freelancers can provide information on their education, work experience, or present a portfolio of their work. Nevertheless, qualities such as trustworthiness, motivation, or quality of work may be problematic to evaluate online (Autor, 2001). Lack of expertise on the side of the employer may even make it impossible to evaluate the quality of the service before the purchase (Pelletier \& Thomas, 2018). Nevertheless, the bargaining power of the employers is disproportional to the ones of workers due to excessive and imposed competition and inherent restrictions at the platform (Anderson, 2017), which limits the financial or human capital gains for most freelancers (Beerepoot \& Lambregts, 2014).

OLM platforms commonly implement reputation systems to overcome the information asymmetry problem for its main customers - the employers. Reputation score is an algorithmically generated score that carries information about the workers' activities and past conduct on the platform. Reputation score is based on evaluations from previous employers and can 
take form of any arbitrary scale (e.g. star-rating). Since the reputation score is public and accessible to potential employers, it provides an immediate signal about employee's quality of work (Dellarocas, 2004). Reputation systems have been equated with the "invisible hand" that facilitates flow of resources to the workers with the best reputation (Goldman, 2011). Some research even shows that reputation systems can offset hiring biases and discrimination (Abrahao et al., 2017; Cui et al., 2019). Experimental evidence shows that being hired for a project and receiving a positive feedback can lead to almost tripled income relative to the control group, which was not hired by the experimenter (Pallais, 2014). Reputation systems can nonetheless lead to socially and individually undesirable consequences. For example, Kas et al. (2019) have shown that since reputation score is obtained only after completed interactions, initial differences between users in the probability to be selected as transaction partner can be heavily consequential for success at OLM platforms. Early differentials in success are likely to accumulate and result in higher likelihood of obtaining work in the future (see Bol et al., 2018; Squazzoni \& Gandelli, 2012) and result in a significant cumulative advantage over time (i.e. the Matthew Effect; DiPrete \& Eirich, 2006; Merton, 1968). The problem of establishing a reputation score may be particularly acute for newcomers to OLM platforms, who strive to obtain the first job with no reputation (Lukac \& Grow, 2020). Such workers are seen as a costly and uncertain investment - a potentially insurmountable entry-barrier to the market for many of the newcomers (Stanton \& Thomas, 2015). The reputation score is considered a strong signal in the hiring process (Lehdonvirta et al., 2018; Snijders \& Matzat, 2019) and has been identified as one of the crucial features of OLM platforms (Wood et al., 2018).

\subsection{The global platform economy}

As offshoring has became an accepted business practice, more researchers investigated motivations behind offshoring (Bunyaratavej et al., 2011). According to transaction cost economics, the primary factor leading firms to offshore services since the first applications were costs savings; leveraging economies of scale at the provider's side (Doh, 2005) and differences in labour costs across geographies (Farrell, 2005). However, cost is only one factor that firms take into consideration (Gefen \& Carmel, 2008). Offshoring strategies are also driven by access to qualified personnel. Especially access to talent and skills is a key (Doh et al., 2009). Bunyaratavej et al. (2007) suggests that a country is more likely to become an offshoring destination when its average wage increases, because it would be able to attract more talented labour. For instance, initial offshoring investments to India were predominantly led by cost considerations, but the (resulting) high-quality of the workforce helped retain and further expand these operations (Dossani \& Kenney, 2003, 2009).

Employers face twofold problems with hiring workers online: First, it is impossible to evaluate how complicated it will be to coordinate remote work with work performed locally (Levy, 2005), and, second, it is hard to decide how to hire the right worker (Pelletier \& Thomas, 2018). Researchers repeatedly highlight that concerns about adverse selection of worker quality are even more amplified in the OLM setting (Agrawal et al., 2015; Pallais, 2014). The distinction between the two approaches - one motivated by costs, the other by access to talent - is specific to the offshored position or task and distinguished by the extent to which it is value-added (Bunyaratavej et al., 2011). The greater the value-added, the more likely the success of the offshoring activity will be dependent on the quality of the service provided 
(Snir \& Hitt, 2003). As a result, the offshoring activity will be mostly motivated by access to high-quality and talented workforce. On the contrary, the lower the value-added, the more likely is cost saving to play a role. For example, basic, back office, and routine activities with low potential for quality variations are expected to be mainly offshored to contractors with an aim to save costs (Youngdahl \& Ramaswamy, 2007). Consequently, requested skills and employer's motivation for offshoring are expected to shape how employees are selected on OLM platforms. In other words, employers' motivations and requested skills, on the one hand, and freelancers' offered skills, on the other hand, are likely to drive the division of the OLM into segments with different processes of work allocation.

\subsection{Towards online labour market segmentation}

Bringing together the micro-mechanisms (human capital theory and transaction cost economics) and macro-mechanisms (platform authoritarianism and bargaining power) explained above, I theorise how these could lead to segmented labour market outcomes in OLMs.

\section{Proposition 1: Structurally delimited segments}

Education and skills constitute key elements in modern economies. In perfect labour markets, according to human capital theory, it is expected that costs and benefits of general training are borne by the workers, while specific training is shared by firms and workers alike (Becker, 1964). However, such perfect allocation mechanism breaks down in presence of labour market frictions (Petrongolo \& Pissarides, 2001). Among others, imperfect information, heterogeneities, limited mobility, and congestion due to large numbers - frictions indisputably present in OLMs. Theories of labour market segmentation (Kalleberg \& Sorensen, 1979; Osterman, 1975; Reich et al., 1973) and dual labour market theory (Doeringer \& Piore, 1971; Piore, 2002) stand up in opposition to human capital theory and describe the labour market as an institution filled with selective barriers controlling access to good and bad jobs and determining job allocation mechanisms. The global platform economy closely mirrors economic developments where companies seek more and more flexibility to meet demand fluctuations through employment (Dörflinger, 2016; Kalleberg, 2003). This creates an open talent economy and on-demand workforce (Bidwell, 2013; Kalleberg, 2012) which suffers the consequences of contingent and unstable work.

Emerging evidence suggests that many of the OLM platforms are highly unequal in terms of employees' earnings (Wood et al., 2018) and that experiences of workers may differ substantially from one to another (Lehdonvirta et al., 2015). Setup of the platforms can create market conditions that offer better access to work and higher remuneration to workers who are already well established at the platform (Lukac \& Grow, 2020). Although gig workers are considered particularly vulnerable to precarity, because of the contingent nature of their work (Kalleberg, 2011), workers with highly specialised skills can seize opportunities brought by online freelancing (Sutherland et al., 2019). Workers that embrace a contract-based arrangement, such as the OLM, often command a pay premium over similarly tasked full-time counterparts (Polivka et al., 2000). Highly skilled workers can benefit widely from the flexible access to work, flexible working hours, and ability to perform work whenever they choose (Spreitzer et al., 2017).

There are two-fold mechanisms at play: on the micro-level, freelancers' skills play a major role in the experience that a freelancer has with the OLM. Employers use different recruiting 
processes based on the skill value-added (Bunyaratavej et al., 2011). On the macro-level, platform authoritarianism ensures preservation of the information asymmetry in favour of the employers by reproducing competition and restrictions as control mechanisms over freelancers (Beerepoot \& Lambregts, 2014; Srnicek, 2017). As a result, on the one hand, predicted by the transaction cost economics theory, employers will prioritise price of labour for selecting low value-added workers; whereas, on the other hand, seeking access to talented workforce, employers will prioritise the platform reputation score as a signal for selecting high valueadded workers. The OLM is hence expected to be composed of structurally delimited segments with different social processes governing the market. These processes - under the structural framework of the market - have an impact upon the allocation of labour between the segments (McDonald et al., 2019). In the context of OLMs, I expect emergence of two segments: $a$ reputation-driven market with high-skilled work, where allocation of work is driven strongly by platform-generated reputation and less by the price of work; and a price-driven market where low-skilled workers engage in a race-to-the-bottom bidding and labour is awarded to workers with the lowest price request.

\section{Proposition 2: Lack of mobility between the segments}

Traditional segmentation literature maintains that mobility between labour market segments remains limited (Reich et al., 1973). Lack of mobility occurs due to institutional barriers between the segments that prevent workers from the secondary segment from penetrating the primary group, while insulating the primary workers from falling to the secondary segment (Doeringer \& Piore, 1971). In the context of OLMs, the ownership of mechanisms of control, such as reputation and experience metrics, certification badges, or recommendations of freelancers remains in hands of the platforms and are in their full autonomy to change as they see fit. As a result, these stand as a structural barrier akin to institutional barriers formulated by the labour market segmentation theory. Immobility on the market manifests itself in terms of constrains in acquiring work in various skill categories. These constraints occur due to organisation of OLM platforms that leads to fragmentation of work into small tasks, where employers lack motivation to develop a long-term relationship with freelancers and hence do not facilitate skill development on platforms (Graham \& Anwar, 2019). This limits workers' ability to gain experience in the high-skill category and to advance their career. Experience and reputation accrued in one skill on the platform has only limited capacity to help with obtaining work in another skill category (Kokkodis \& Ipeirotis, 2016).

Individual level mechanisms also play a role; lack of training opportunities and impossibility to use and grow professional skills necessarily endangers peoples' future job security, since they are unable to retain niche in employment and are thus eluded by opportunities for upward mobility (Standing, 2011). This does not necessarily mean that there is no mobility between the segments whatsoever; rather that the mobility between the segments is considerably lower than mobility within the individual segments (Osterman, 1975). As a result, ability of lowskilled workers to upgrade to high-skilled work via the platform is very restricted (Graham \& Anwar, 2019). The inability to expand one's skills and transcend the barrier between lowand high-skill work at the platforms constitutes the boundary for mobility between segments at OLMs.

When performing work at OLMs, I expect workers to be using only a small group of skills that are regardless likely to occur together - e.g. graphic design (as a general skill) and Photoshop (as a specific software skill used for graphic design) - rather than with distant and unrelated 
skills - e.g. graphic design and translation. As a result, I expect that majority of skills that will be used by a single worker at OLMs will come from a single skill cluster or closely related skills (defined and operationalised further below).

\section{Proposition 3: Workers and disadvantage}

Conditions of work differ significantly between the labour market segments. Traditional segmentation theories often investigate disadvantages attached to membership in the secondary segment, such as social exclusion, higher risk of poverty, or worsened health outcomes. These clearly add political and social relevance to the notion of labour market segmentation (Häuserman \& Schwander, 2012). In context of OLMs, the main differences between the segments are likely to emerge as consequences stemming from the previous propositions - structural delimitation of segments aligning with skills and lack of mobility between segments. I expect that the reputation-driven segment will have higher average income per project and lower number of competing bidders per project than the price-driven segment. Apart from objective indicators of disadvantage, I also expect that being a member of the price-driven segment will lead to feeling of poorer ability to negotiate their salary and therefore lowered feeling of being remunerated fairly. The main source of this could be the higher competition and also lower average income per project. As a consequence, workers in the price-driven segment are expected to feel more stressed, be susceptible to tight deadlines and have lower say over deciding when to work (Eurofound, 2019).

To sum up, duality of work arrangements by skills frequently occurs in the recent literature on employment. Although it is beyond doubt that skills are socially constructed categories (see Hanley, 2014), they provide a useful lens for explaining differentiated labour market outcomes. For example, Spreitzer et al. (2017) review the literature on alternative work arrangements and conclude with two images of segmented workforce depending on skills: On the one hand, high-end workers with specialised knowledge are likely to enjoy flexibility by alternative arrangements, because their "high skill is a source of power that allows them to shape the work conditions they desire" (Spreitzer et al., 2017, p. 485). On the other hand, low-skilled workers are likely to experience the full scale of precarity as flexibility is predominantly used to transfer risks from the firm to the low-skilled workforce (Hacker, 2019). Low-skilled workers tend to be in high supply, which undercuts their wages (Bidwell, 2013) and marginalises their power in wage negotiations. Similarly, research in online recruiting shows a duality in recruiting between high- and low-skill, resulting into "winner-take-all" dynamics (McDonald et al., 2019). In a similar vein, separation based on skills is likely to penetrate also the OLMs and determine outcomes for individual workers. This segmentation runs not only within but also across gig economy platforms; OLM platforms (Fiverr, Freelancer or Upwork) specialise more in skills that could be considered as high-level, whereas micro-taksing platforms (e.g. Amazon MTurk) gather demand for low-level skills. Consequently, skills are even more central to the question of labour market segmentation than ever, especially in the context of the ongoing digitisation and automation that the world has been witnessing over the last decade. 

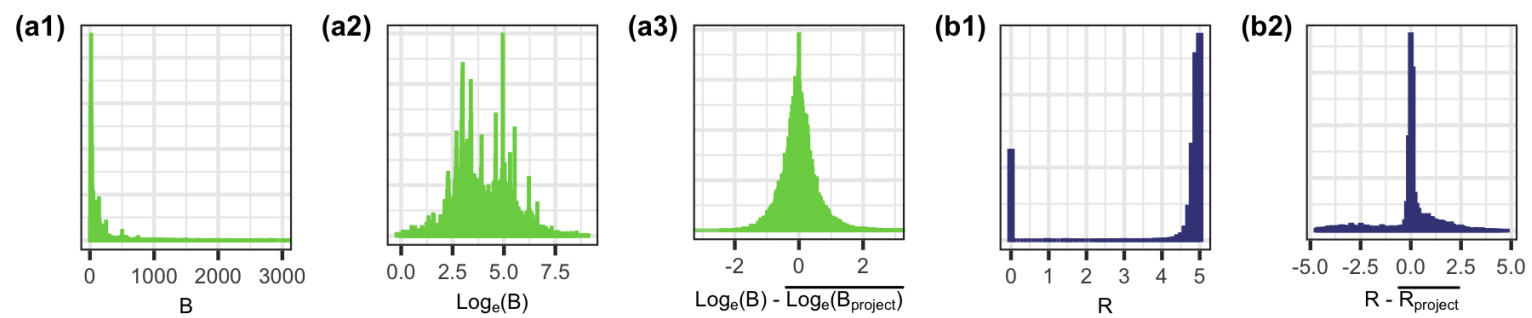

Figure 1: Distribution of variables in the dataset. From left to right: (a1) heavily right skewed distribution of bids $B,(\mathbf{a 2})$ natural logarithm of bids $\log _{e}(B)$, (a3) project mean centered distribution of $\log _{e}(B)$, (b1) bimodal distribution of reputation $R$, (b2) project mean centered distribution of $R$.

\section{Research design}

\subsection{Data}

In this section, I present two datasets that I used for analysis. First, for the web-scraped dataset, I present data collection methodology and give a high level overview, focusing specifically on the variables used in the following models. Second, for the survey dataset, I provide a short description of the dataset and its survey methodology. The web-scraped data offer information about worker's behaviour in online labour markets and skills they use, while the survey data offer information about worker's perception of work quality on dimensions such as fairness of pay, tightness of deadlines, and stress. Use of these two datasets corroborates the evidence from two independent sources and provides a more holistic view on the question of online labour market segmentation than just one source of data could provide alone.

Web-scraping The data were collected from an undisclosed OLM platform, which belongs among the largest players in the field (more about ethics and data availability, see section Ethics and Data Availability in the Appendix). Data collection proceeded as follows: First, I collected a random set of URL addresses of projects which were open for at least one month at the website (to give freelancers and employers enough time to decide whether they want to start a project or not). Then, data collection was spread over the whole month of November 2019 to avoid any burden the platform's servers. The web-scraper collected inputs on 12,123 projects with 188,622 bids, coming from 37,127 unique users from 172 countries. I removed jobs where no winner was chosen or all bidders were winners. I used only auctions that were set up as paid per hour to avoid interference due to different modes of remuneration. It is important to note that my data collection does not include users who were inactive in the sampled period and did not cast any bids or deactivated their accounts prior to my data collection. This raises a general question about selective dropout from OLM platforms, especially for workers who did not succeed to find any work for extended periods of time. In the future work, researchers might be able to answer this question by using periodic data collections to identify users who deactivated their accounts.

Based on the web-scraped data, I was able to extract the following information about the projects and workers: 

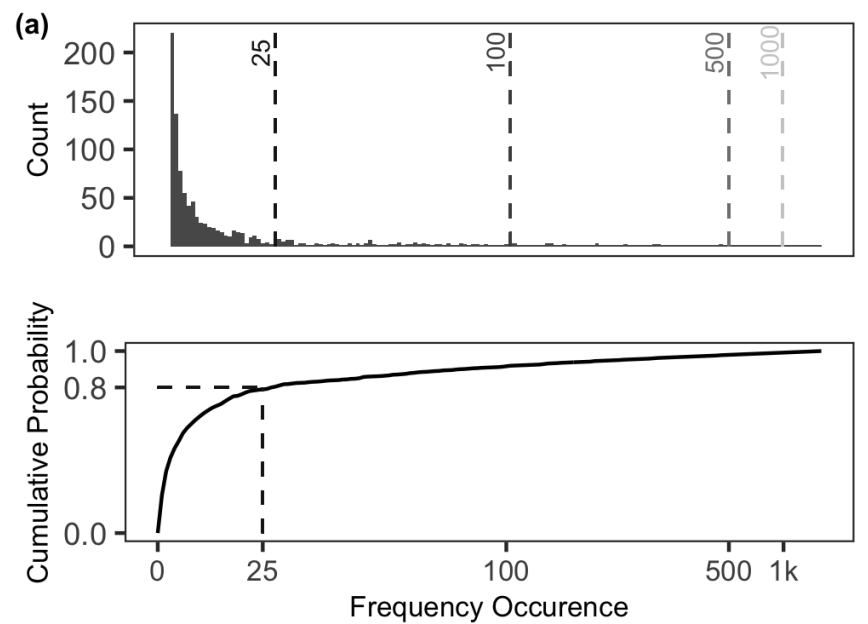

(b)

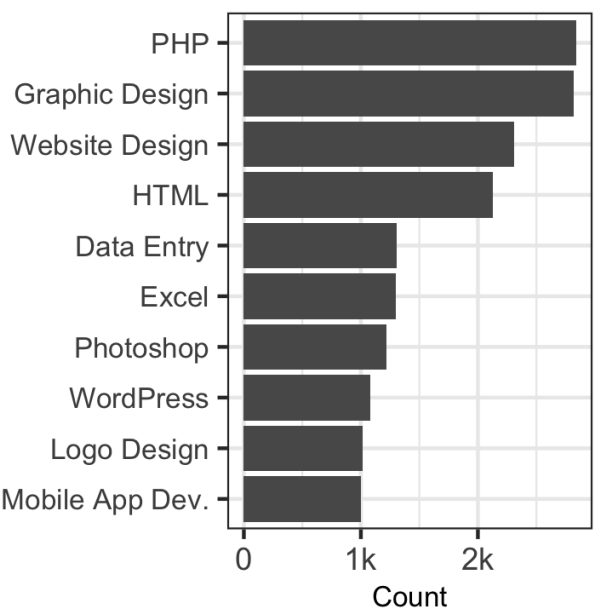

Figure 2: Panel (a) The upper plot shows a histogram of skills occurrence frequency -i.e. value of 1 on the $x$-axis means that the skill occurred only once and the $y$-axis plots how many of skills occurred once. As can be seen, large majority of skills occurred very few times, while only a few "super-skills" occurred more than 100-times. The bottom panel plots a cumulative function of the upper plot to show the $\%$ of skills that occurred less than $x$-times. Specifically, about $80 \%$ of the skills occurred less than 25-times. Panel (b) Skills that occurred more than 1000-times - i.e. "super-skills".

1. Skills: I extracted skill tags from the project's description. Based on the platform's algorithmic suggestions (a curated list of previous skills), employers are obliged to select at least one skill when creating the project (examples of skills are mentioned in the Table 1 ). Used skills are also shown in freelancers' profiles.

2. Bids: I recorded bids placed to a specific project by freelancers. Bid's currency depends on the project, hence all bids were subsequently standardised to USD based on platform's exchange rate.

3. Reputation: I extracted reputation scores of freelancers at the time of placing the bids. The reputation can therefore differ for the same freelancer across different projects due to intermediate completion of projects and obtaining feedback that alters one's reputation score.

4. Winner: I record which freelancer received the project. The platform allows several winners per project, for example if the employer needs more freelancers to perform the work.

Assuming that employers evaluate freelancers on the relative information they see in the project and not on the global information across all freelancers at the platform (Lazear et al., 2018), I took a natural logarithm of bids $(B)$ and subtracted the average bid for the respective project. Reputation score $(R)$ was project mean centered similarly to bids. For distributions of variables, see Figure 1.

The collection of projects comprised of 1,053 unique skill labels. A project allows mentions of multiple skills, therefore skills are not mutually exclusive. Distribution of skill frequencies 
is highly skewed, as about $80 \%$ of the skill labels occurred less than 25 times (see part (a) of Figure 2). Only a small fraction of skills occurred more than 1,000 times (part (b) of Figure 2) in the sampled period, yet these "super-skills" can account for the majority of projects used on the platform. As a result, for the analysis, I dropped skills that occurred fewer than 10 times. This substantially diminishes the computational burden for the network analysis and still accounts for $96.13 \%$ of all skill occurrences across all projects. The final number of skills used for the analysis is 388 .

Survey data: COLLEEM survey The second source of data used for this project is an online panel survey on digital labour platforms, commissioned in 14 European countries ${ }^{1}$. Fieldwork was carried out in second half of June 2017, with final sample of 32,409 respondents. The survey aimed to be representative of all Internet users between 16 and 74 years old in the selected countries. Sampling frame was based on a commercially available list of Internet users in the selected countries, with non-probability quota sampling of respondents by gender and age groups. Post-stratification weights were computed by adjusting the sample proportions to known population proportions of level of formal education, frequency of Internet use and employment status and used throughout my analysis to correct for self-selection and nonprobability sampling. For more information about the survey, see Pesole et al. (2018).

For the analysis, as I am interested only in users who have experience with OLMs, I kept only respondents who answered positively to the question whether they provided services "via online platforms, where you and the client are matched digitally, payment is conducted digitally via the platform, and work is location-independent, web-based ${ }^{2}$ (e.g. Upwork, Freelancer, Timeetc, Clickworker, PeoplePerHour and others)." The resulting sample size is 2,757 (8.5\% of the original sample).

Two sets of measures are used in the analysis: First, I calculate the number of skills used during respondent's experience online. This was calculated as a count of mentioned skills out of eight categories. I excluded location-dependent skills, such as transportation, delivery, or on-location services, since these clearly do not pertain to the question of skill use at OLMs. Second, I use a set of questions focused on working conditions at online platforms. Respondents were asked to express their agreement (strongly agree, agree, partly agree/disagree, disagree, strongly disagree, NA) with a battery of statements, out of which I selected a final list of statements based on the theory explained:

1. I decide myself what price to charge for my services

2. I am remunerated fairly

3. I can decide when to work

4. I often face stressful situations

5. I often have tight deadlines

These questions are aimed to represent two strands of disadvantages faced by workers online. On the one hand, first two question tap into perceived differences in workers' remuneration, which can clearly stem from different segments in which workers find themselves online. On

\footnotetext{
${ }^{1}$ Germany, Netherlands, Spain, Finland, Slovakia, Hungary, Sweden, United Kingdom, Croatia, France, Romania, Lithuania, Italy, Portugal

${ }^{2}$ Emphasis included in original survey question formulation
} 
the other hand, the bottom three questions touch the lack of autonomy of online workers and consequences stemming thereof.

\subsection{Statistical modelling: Regression mixture model}

To model segmentation of OLMs, I apply finite mixtures of regression models (McLachlan $\&$ Peel, 2000). These are exploratory models to investigate differences in effects ( $x$ on $y$ ) between unobserved groups (see Lukac et al., 2019, for use of latent class model for labour market segmentation). These unobserved groups represent subgroups of respondents for whom the effect of the attribute $x$ differs in magnitude or direction from the other groups.

More formally, consider a sample of $N_{p}$ projects and $N_{i p}$ bids nested within projects. Dependent variable $y_{i p}$ is a binary variable denoting whether the specific proposal of freelancer $i$ on project $p$ was selected as winning or not. The model contains two observed independent variables: (1.) Bid of freelancer $i$ on project $p$, denoted as $B_{i p}$; specifically its project mean centred logarithm, see Figure 1 part (a3), which I will refer to as $B_{i p}$ for the sake of brevity; and (2.) reputation of freelancer $i$ at the time of bidding on project $p$, denoted as $R_{i p}$; specifically, its project mean centred version shown in Figure 1 part (b2), which I will refer to as $R_{i p}$. Independent variables are members of matrix $\mathbf{x}=\left(\mathbf{B}_{\mathbf{i p}}, \mathbf{R}_{\mathbf{i p}}\right)$.

For comparative purposes, I start with a simple pooled logistic regression model for measuring the effect of $B_{i p}$ and $R_{i p}$ on the probability of winning a project:

$$
\log \frac{P\left(y_{i p}=1\right)}{1-P\left(y_{i p}=1\right)}=\beta_{0}+\beta_{B} B_{i p}+\beta_{R} R_{i p}
$$

Parameters of $\beta_{B}$ and $\beta_{R}$ can be interepreted as in a standard logistic regression, with linear transformation of the log odds - the ratio of the probability of winning a bid $P\left(y_{i p}=1\right)$, divided by the probability of the bid losing $1-P\left(y_{i p}=1\right)$. The parameters denote a one unit change of the respective independent variable in log-odds ratio for winning a project. As $B_{i p}$ is logged and project mean centred, a one unit increase is equivalent to a percentage point increase above the group mean. Similarly, $R_{i p}$ is project mean centred, hence one unit increase in reputation means one unit increase above the project mean.

Given the suspicion that the population is not homogeneous in the effects of $\beta_{B}$ and $\beta_{R}$, we extend the simple model into a mixture of regressions. Membership in the unobserved group (latent class) is denoted by $k$, where $k=1,2, \ldots, K$. Contribution of each class to the overall density is $\pi_{1}, \pi_{2}, \ldots, \pi_{K}$, which also represents the prior probability of being in the respective latent subgroup $k$. Finally, $\theta_{k}$ is the latent class specific vector of all parameters. The mixture of regressions model is given by

$$
\begin{gathered}
f(y \mid \varphi, \mathbf{x})=\sum_{k=1}^{K} \pi_{k} f_{k}\left(y_{k} \mid \theta_{k}, \mathbf{x}\right) \\
\pi_{k} \geq 0, \quad \sum_{k=1}^{K} \pi_{k}=1
\end{gathered}
$$


where $\varphi=(\pi, \Theta)$ denotes a vector of all parameters to be estimated. Assuming the dependent variable comes from a binomial distribution, the model is written as the following class-specific equation for each $k$ :

$$
\log \frac{P\left(y_{i p}=1\right)}{1-P\left(y_{i p}=1\right)}=\beta_{0 k}+\beta_{B k} B_{i p}+\beta_{R k} R_{i p}
$$

where $\beta_{0 k}$ is a class-specific intercept, $\beta_{B k}$ and $\beta_{R k}$ are a class-specific effects of bid $\left(B_{i p}\right)$ and reputation $\left(R_{i p}\right)$ respectively. Such model allows the parameters of $\beta_{B k}$ and $\beta_{R k}$ to vary by the unobserved class, which reflects the theory of OLM segmentation that work allocation mechanisms are different between different segments.

The hypothesis about presence of unobserved classes with different effects of $\beta_{B k}$ and $\beta_{R k}-$ i.e. segmentation hypothesis - is tested by comparing model fit indices of models with $k$ and $k-1$ components. Despite various suggestions, to this day, there is no consensus for determining the number of classes in mixture modelling (see Nylund et al., 2007). The commonly used $\log$ likelihood difference test assumes the difference is $\chi^{2}$ distributed, but these conditions are most likely not being met, hence $p$ values are likely inaccurate (McLachlan \& Peel, 2000). Nevertheless, simulation study by Nylund et al. (2007) shows that the Bayesian Information Criterion (BIC) and the bootstrap likelihood ratio test (BLRT, see McLachlan and Rathnayake, 2014) are consistent indicators of the number of classes across various mixture models. I will rely on their findings and use BIC and BLRT for testing the first segmentation hypothesis about the presence of unobserved sub-populations. Nevertheless, for transparency, I also report other commonly used indices, such as the naive log likelihood difference test and the Akaike Information Criterion (AIC).

\subsection{Network model of skills}

I construct a skill co-occurrence network representing the use of skills by workers. The network is constructed only from entries when a worker won a job. The rationale is that bidding for a job does not necessarily mean that a worker has experience with the skill the project involves. However, having won and performed the work (regardless of the final satisfaction of the employer), I assume that this worker has the skill in question. In this network, there are two types of nodes: workers $\left(N_{w}=2,351\right)$ and skills $\left(N_{s}=388\right)$; and edges are undirected but weighted proportionally to the number of times worker used a specific skill. We represent the network by its association matrix $A_{w s}$, with elements

$$
A_{w s}= \begin{cases}r & \text { if } w \text { used skill } s \\ 0 & \text { if } w \text { did not use skill } s\end{cases}
$$

where $r \geq 1$ and represents the number of times a worker $w$ used skill $s$. The two mode network is subsequently projected into a unimodal adjacency matrix $A$ by multiplying the association 


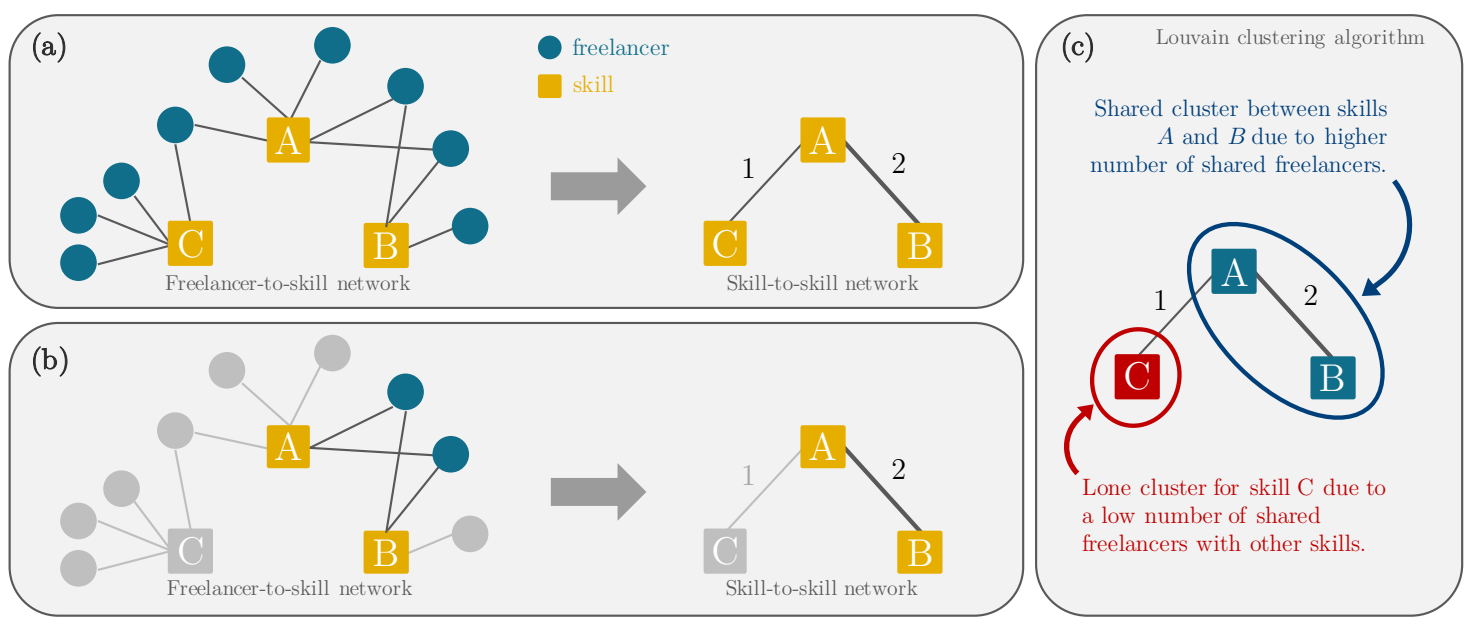

Figure 3: Panel (a) Two-mode network projection to a unimodal network yields a weighed network (see (b)) with weights proportional to the number of shared nodes. Panel (c) shows a stylised application of the Louvain clustering algorithm.

matrix $A_{w s}$ by its transpose: $A=A_{w s}^{T} A_{w s}$. The resulting skill co-use network $A$ is a unimodal network with $N_{s}=388$ nodes representing skills and edges weighted proportionally to co-use of skills (see Figure 3, panels (a) and (b) for visualisation of this transformation).

Skills tend to cluster together into logical specialisation categories. These parallel our universal inclination to partition complex objects into manageable and socially understood classifications (Fiske \& Taylor, 1991); e.g. someone known as graphic designer will have used skills such as "Photoshop", "Adobe Illustrator", and "Graphic Design", hence these three nodes are expected to occur together more often than expected at random. In order to extract clusters of skills that occur frequently together, I relied on network community detection algorithm (see Newman \& Girvan, 2004, and Figure 3, panel (c)). I used communities extracted by Louvain algorithm (Blondel et al., 2008), which optimises for modularity ${ }^{3}$ in two hierarchical steps: First, it performs an initial clustering by looking for "small" communities locally. Second, it collects the nodes belonging to the same community and drafts a new network with nodes representing the extracted communities. These steps are performed iteratively until the maximum modularity is reached. The resulting clusters are shown in Table 1 and are labelled according to the skills that were clustered together.

\section{Results}

\subsection{Structurally delimited segments}

A segmented labour market manifests itself as structurally delimited between segments with different characteristics and with different social processes that influence allocation of labour.

\footnotetext{
${ }^{3}$ Modularity can lie in the range $[-1,1]$ (Brandes et al., 2008). If positive, the number of edges within groups exceeds the number expected solely by chance. Modularity reflects the concentration of edges within modules compared with random distribution of links between all nodes regardless of modules
} 


\begin{tabular}{ll}
\hline Skill Cluster & Skills examples \\
\hline Writing \& Research & Academic, Business Analysis, Copywriting, Creative, Legal, Re- \\
& search, Statistics, .. \\
Programming \& Database & Android, AngularJS, C, Fullstack Development, Git, Java, Python, \\
& SQL, Swift, ... \\
Web Design & API, Backend Development, CSS, eCommerce, HTML, Joomla, \\
& PHP, WordPress, ... \\
Assistance & Bookkeeping, Microsoft Office, Data Processing, Data Scraping, Ex- \\
& cel, Virtual Assistant, ... \\
Graphic Design & Adobe Illustrator, Brochure Design, Business Cards, Graphic De- \\
& sign, Photoshop, ... \\
Design \& Animation & 3D Animation, AutoCAD, ExplainerVideos, HomeDesign, Interi- \\
& orDesign, Video Editing, \\
Translation & Arabic, Danish, English, French, German, Hindi, Japanese, Polish, \\
& Russian, Swedish, ... \\
Advertising \& Marketing & Call Center, Digital Marketing, Google Adwords, Instagram, Pin- \\
& terest, Telemarketing, ... \\
\hline
\end{tabular}

Table 1: Examples of skills for each extracted skill cluster

In the first step, I estimated a logit regression on the collected sample (see Table 2) where probability of receiving a project is regressed on project-standardised bid and project-centered reputation score. Obtained coefficients align with previous literature and show intuitive findings: First, the higher the bid than the average of bids for the particular project, the lower the probability of winning. This goes in line with the theory of transaction cost economics, showing that rationale behind hiring freelancers online is often driven by cost saving (Bunyaratavej et al., 2011). Second, the higher the reputation compared to other bidders for the project, the higher the probability of winning. This finding is in line with the theory of talent access as a rationale for hiring freelancers online (Bunyaratavej et al., 2007; Doh, 2005).

In order to test whether the sample of OLM projects contains sub-populations with different processes of work allocation, I estimate a two-component $(k=2)$ mixture of regressions, where the effects of bid and reputation on probability of winning are assumed to come from two unobserved classes. Inspecting the model fit indices, the two-component mixture of regressions model significantly improves the model fit in terms of the likelihood ratio test (LRT statistic $=47.245$, assuming $\chi^{2}$ distribution at 11 degrees of freedom, $p<0.001$ ), which is also further confirmed by the bootstrapped likelihood ratio test $(p<0.05)$. The mixture model shows a better model fit in terms of $\mathrm{BIC}(\Delta \mathrm{BIC}=-46.327)$ and $\mathrm{AIC}(\Delta \mathrm{AIC}=-25.245)$ than the pooled model. These statistical tests show evidence for the presence of unobserved groups in the population of OLMs that have different work allocation mechanisms. To ensure robustness of these findings, I estimated also a three-component $(k=3)$ mixture, but it showed worse model fit than the two-component mixture (LRT statistic $=14.939$ at 14 degrees of freedom, bootstrapped LRT $p>0.05, \Delta \mathrm{BIC}=78.633, \Delta \mathrm{AIC}=7.061)$.

The two-component model extracts two segments (shown in Table 3). Based on the interpretation of the estimated coefficients, the first segment is labelled "price-driven" and the second segment as "reputation-driven" segment. The price-driven segment is distinguished markedly by a strong effect of bid $\left(\beta_{B}=-2.089\right)$ and a negative effect of reputation $\left(\beta_{R}=-0.564\right)$ - an opposite sign in comparison to the pooled model - on the probability of winning. The price seems to be a leading driver of work allocation in this segment and, surprisingly, higher than average project reputation has a detrimental effect on the probability of winning in this seg- 
(a)

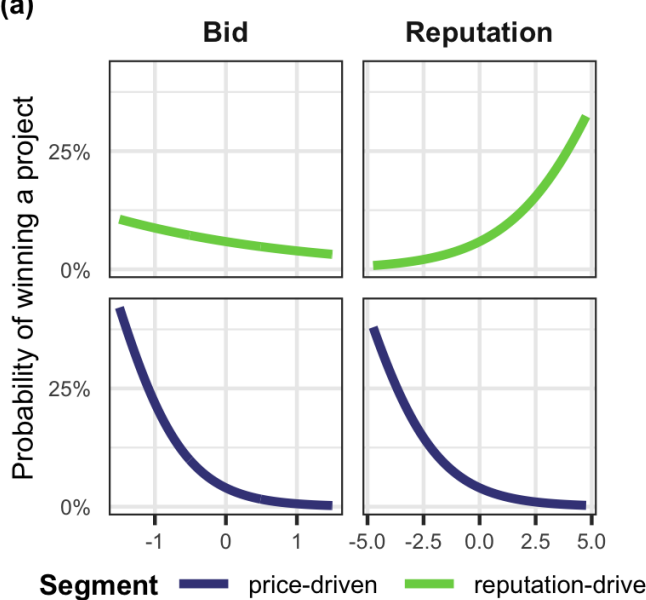

(b)

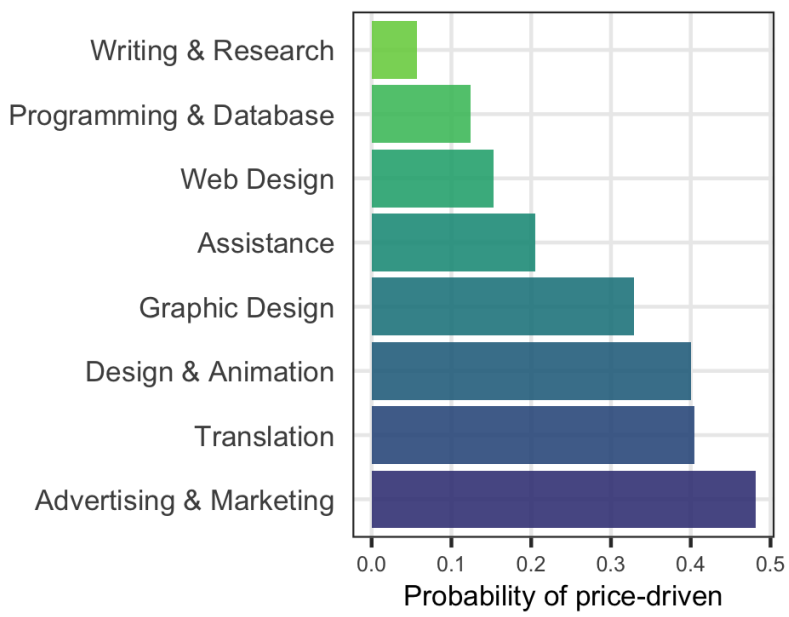

Figure 4: Panel (a) Effects of bid and reputation on predicted probability of winning a project in reputation-driven (top) and price-driven (bottom) segments. Panel (b) Probability of a project belonging to a price-driven segment by skill-clusters extracted from the skill cooccurrence network. Clusters at the top are least likely to occur in the price-driven segment, while clusters at the bottom are the most likely to occur in the price-driven segment.

ment. Potential interpretation is that many of the projects in this segment were allocated to workers with no or low reputation. Workers in this segment are selected because they bid low amounts in order to build up reputation, which mirrors employers' motivation to save costs.

The reputation-driven segment is differentiated by a relatively low and marginally significant effect of the bid $\left(\beta_{B}=-0.389, \mathrm{p}\right.$-value $\left.=0.047\right)$ and a strong effect of reputation $\left(\beta_{R}=0.419\right)$ on the probability of winning. On the contrary to the price-driven segment, reputation is the decisive driver of work allocation in this segment and price has fairly low importance. This segment reflects motivation of employers who are seeking talented workers, being relatively indifferent to the price they pay. Comparisons of fitted probabilities of winning given both independent variables for both segments are displayed in Figure 4 panel (a).

In line with the theory, one segment is driven predominantly by the cost of labour, while the other segment by access to workers with high reputation. As I hypothesised further, the segment driven by costs of labour will contain a large proportion of low-skilled work, while the reputation-driven segment will contain mainly high-skilled work. As shown in Figure 4 panel (b) (see specific skill examples for each cluster in the Table 1): on the one hand, projects requiring skills such as writing and research $(5.6 \%)$, or programming and databases $(12.4 \%)$ have the lowest probability to be in the price-driven segment. On the other hand, online advertising and marketing (48.1\%) or translations (40.5\%) are at the highest risk of having a project from the price-driven segment. As we theorised, high value-added skills, such as research, statistical analysis, creative writing, or programming are allocated to workers with the intention to attract talent with lower considerations of the price. Low value-added skills, such as telemarketing or management of online advertising through Instagram, Pinterest, or other social media are in high proportions allocated to workers according to their ability to compromise on the price of labour.

Prevalence of price-driven and reputation-driven segments is estimated to be $17.10 \%$ and 


\begin{tabular}{|c|c|c|c|}
\hline & \multicolumn{3}{|c|}{ Logit Model } \\
\hline & $\begin{array}{l}\text { Dependent } \\
\text { (1) }\end{array}$ & $\begin{array}{c}\text { variable: Winn } \\
(2)\end{array}$ & $\begin{array}{c}\text { g a project } \\
(3)\end{array}$ \\
\hline $\operatorname{Bid}\left(\beta_{B}\right)$ & $\begin{array}{c}-0.665^{* * *} \\
(0.138)\end{array}$ & & $\begin{array}{c}-0.689^{* * *} \\
(0.138)\end{array}$ \\
\hline Reputation $\left(\beta_{R}\right)$ & & $\begin{array}{c}0.149^{* * *} \\
(0.038)\end{array}$ & $\begin{array}{c}0.159^{* * *} \\
(0.038)\end{array}$ \\
\hline Constant & $\begin{array}{c}-2.629^{* * *} \\
(0.057)\end{array}$ & $\begin{array}{c}-2.616^{* * *} \\
(0.057)\end{array}$ & $\begin{array}{c}-2.653^{* * *} \\
(0.059)\end{array}$ \\
\hline Observations & 4,947 & 4,947 & 4,947 \\
\hline Log Likelihood & $-1,236.674$ & $-1,240.967$ & $-1,227.765$ \\
\hline
\end{tabular}

Table 2: Logistic regression model for winning a project

\begin{tabular}{lcc}
\hline \hline & \multicolumn{2}{c}{ Mixture of Logit Regressions $(k=2)$} \\
\cline { 2 - 3 } Segment label & Dependent variable: & Winning a project \\
Price-driven segment & Reputation-driven segment \\
\hline Bid $\left(\beta_{B}\right)$ & $\mathbf{1 7 . 1 \%}$ & $\mathbf{8 2 . 9 \%}$ \\
& $-2.089^{* * *}$ & $-0.389^{* *}$ \\
& $(0.574)$ & $(0.195)$ \\
Reputation $\left(\beta_{R}\right)$ & $-0.564^{* * *}$ & $0.419^{* * *}$ \\
& $(0.151)$ & $(0.070)$ \\
& & \\
Constant & $-3.237^{* * *}$ & $-2.765^{* * *}$ \\
& $(0.277)$ & $(0.087)$ \\
& & \\
\hline
\end{tabular}

\begin{tabular}{lc}
\hline Observations & 4,947 \\
Log Likelihood & -1204.142 \\
\hline \hline Note: & ${ }^{*} \mathrm{p}<0.1 ;{ }^{* *} \mathrm{p}<0.05 ;{ }^{* * *} \mathrm{p}<0.01$
\end{tabular}

Table 3: Finite mixture of logit regressions for winning a project 
$82.90 \%$ respectively. This shows that majority of projects on the investigated platform are allocated based on freelancer's platform generated reputation. A low prevalence of the pricedriven segment at the selected OLM platform underlines the notion that OLMs are not only segmented within platforms, but also across platforms (Schor et al., 2020). OLM platforms (including the selected one) are known to distribute comparatively high-level work in comparison with micro-tasking platforms (e.g. Amazon MTurk). Employers and workers are therefore likely to self-select into platforms depending on their demands and competences. Finally, distinction between high and low value-added skills seem to differentiate quite strongly among the two segments. As a result, I conclude that the investigated OLM platform clearly shows evidence of structurally delimited segments with different social processes governing allocation of labour and these segments are strongly determined by skills.

\subsection{Limited mobility}

In order to investigate the limited mobility hypothesis of OLM segmentation, I look at the distribution of segments among workers that won at least two projects. This yields an estimate of the probability that a freelancer performs projects from same or different segments - i.e. that freelancers are mobile across OLM segments.

The results show that $77.8 \%$ of users received only one project and $22.2 \%$ received two and more projects. Within the group of users who received only one project, $78.5 \%$ of these projects were from the reputation-driven and $21.5 \%$ from the price-driven segment. Workers who obtained two and more projects in the sampled period were substantially more likely to come from the reputation-driven segment $(91.4 \%)$ and only very few came from the pricedriven segment (1.3\%). Most importantly, only $7.3 \%$ of users received work from different segments. This serves as strong evidence for a lack of mobility between segments, as freelancers seem to be much more likely to receive work from the same segment rather than from two different segments.

To further inquire into the question of limited mobility between OLM segments, I constructed a skill co-occurrence network, which shows which skills were used together by the same worker at the OLM platform. An edge (link) between two nodes (skills) demonstrates that these two skills were used by the same user. The more often two skills occurred together, the closer the nodes are in the network. The resulting network (see Figure 5) shows a high level of clustering $^{4}$. The global clustering coefficient is estimated at 0.235 , meaning that skills indeed tend to occur together in clusters. For comparison, expected global clustering coefficient of a network with edges distributed randomly between nodes (and similar network statistics) is approximately 0.038 .

In order to analyse this clustering, I applied Louvain community detection algorithm (Blondel et al., 2008). The resulting clusters are shown by different colours and labelled according to Table 1. Estimated modularity of the observed skill co-occurrence network is 0.617 , meaning that $61.7 \%$ of skill co-occurrence happens within respective skill-clusters. This serves as evidence that users of the OLM platform seldom cross the boundaries of skill-clusters and, as segments are strongly related to skills, this serves as further evidence for the hypothesis of limited mobility between OLM segments.

To corroborate the evidence even further, I inspect the self-reported number of used skills

\footnotetext{
${ }^{4}$ If skills $B$ and $C$ are used with skill $A$, the probability of $B$ and $C$ being used together is higher than just by random
} 


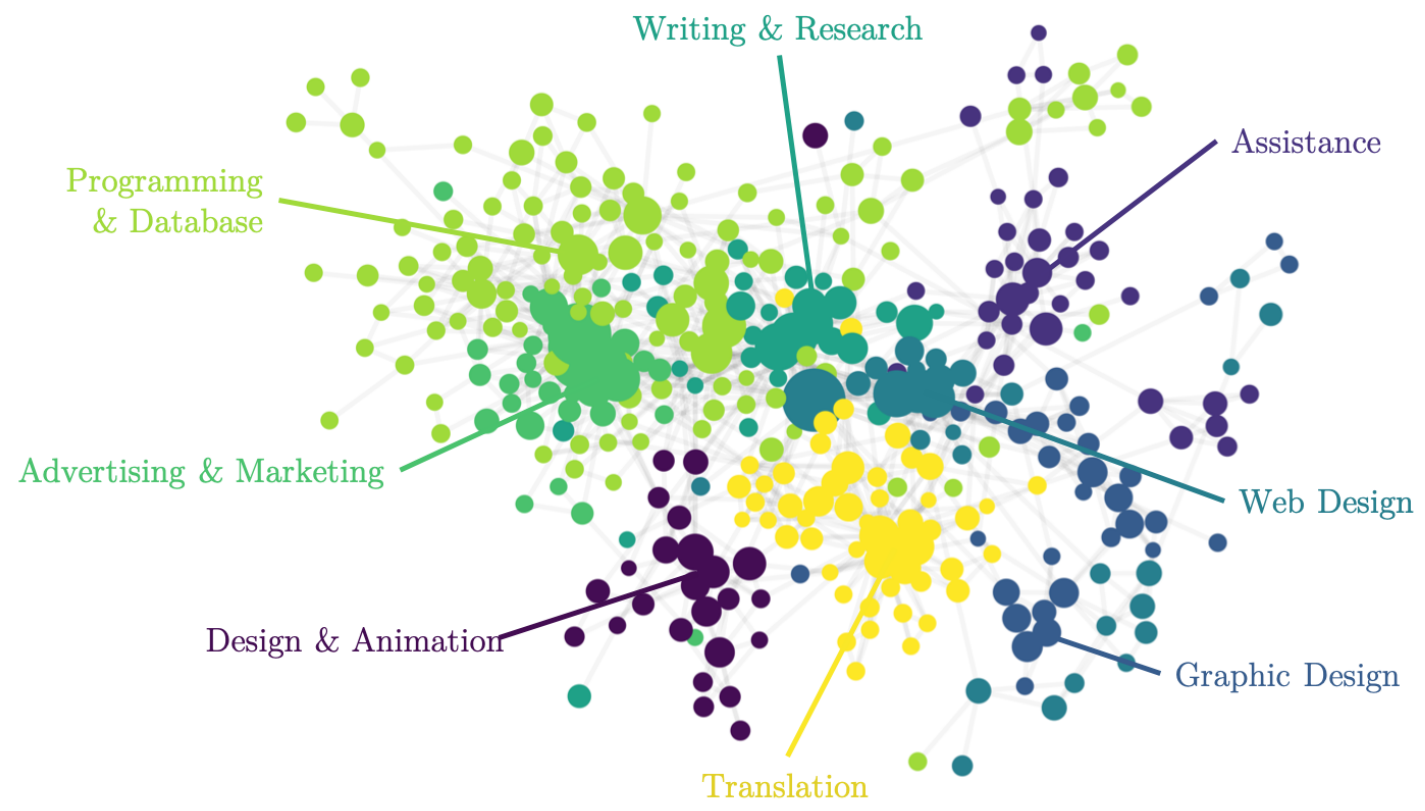

Figure 5: Skill co-occurrence network; each node represents a skill on the platform, size is proportional to the frequency of skill occurrence. Two nodes are connected by a tie if respective skills were used by the same freelancer on the platform. Skill clusters extracted by Louvain algorithm (see Section 3.3) are coloured accordingly and labelled.
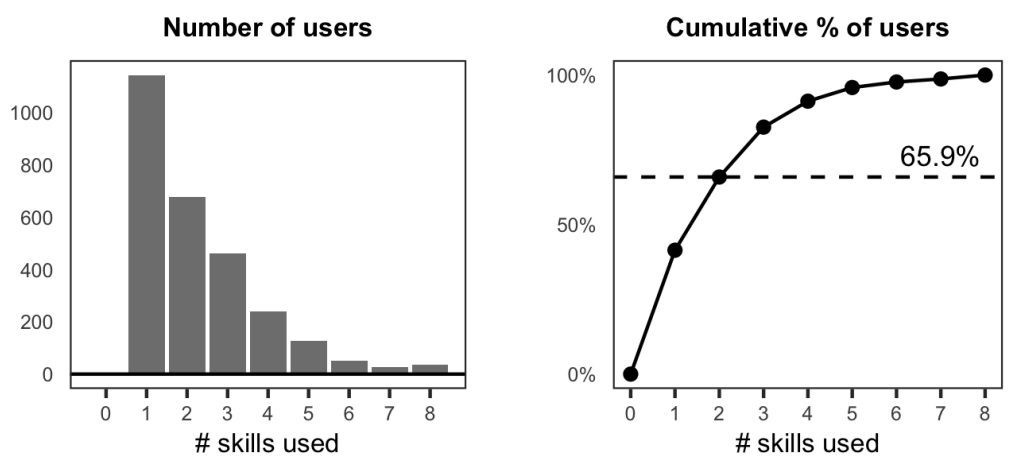

Figure 6: Skill use estimated from survey data (see Section 3.1) (Left) Number of skills used by freelancers at OLMs and (Right) cumulative \% of skill use, showing that about $65.9 \%$ of users used two or less skills in their experience at OLMs. 
at the platforms per worker from the survey data. Given the theory and results from the web-scraped data, I expect that majority of workers have used only one or two skills. This can be seen in Figure 6, where the frequency of the number of used skills (defined by the COLLEEM survey) is plotted. The plot of cumulative frequencies is displayed on the right and shows that $65.9 \%$ of workers used only one or two skills. This estimate is close to the modularity estimate from the web-scraped data and further confirms the notion of lack of mobility between OLM segments.

Given the presented evidence, I conclude that there is limited mobility of freelancers between different OLM segments. The findings show that mobility between segments is not impossible, yet it is considerably lower than mobility within the segments. Empirical data mirror the concerns of work fragmentation literature (see Rubery et al., 2009), as workers are stuck with their respective skill-sets and OLM platforms constrain their ability to gain experience and develop skills to advance their future careers (Graham \& Anwar, 2019). As a result, freelancers are susceptible to be attached to an OLM segment with a specific set of work allocation rules in the long-run (which is left for further inquiry).

\subsection{Differentiation between workers}

In the last section, I investigate work conditions of freelancers in different segments and explain whether these can lead to a specific disadvantage. The results are split into two sections: First set of results comes from the web-scraped data, estimating the average price per project and competition in different segments. Second set of results comes from survey data, where I use selected skill groups as proxies for extracted segment (price-driven segment is represented by "Sales and Marketing" and reputation-driven segment by "Software Development and Technology") and investigate subjective levels of autonomy in price setting, deciding working time, stress and how often one faces tight deadlines.

The estimates in Figure 7 panel (a) show that the average remuneration for a project in the reputation-driven segment is $76.9 \%$ higher than the average remuneration in the pricedriven segment. This finding agrees with the theory, as a segment that is dependent on reputation and experience rather than on price is expected to have higher remuneration levels. Contrary to initial expectations though, the number of bids - i.e. the competition - in the price-driven segment is not significantly higher than in the reputation-driven segment. Initially, I argued that the reputation-driven segment will be more "selective" and hence lead to lower competition, similarly to how primary segment is shielded in offline labour markets. However, this dynamic does not seem to extend to OLMs. In primary segment in offline labour markets, an opportunity to apply and be considered for the best positions is often extended only to a select group of candidates. In contrast, virtually anyone can apply for a project online.

Results from survey data are shown in Figure 7 panel (b). Workers in the skill-group representing the reputation-driven segment ("Software Development and Technology") are significantly more likely to agree that they can decide what price to charge for their services as well as feel remunerated more fairly than the group representing the price-driven segment ("Sales and Marketing"). This is a notable finding given that there was no significant difference in competition between the two segments in the web-scraped data. Even despite similar levels of competition, workers with skills that occur in the reputation-driven segment feel more power to decide price of their work and feel more fairly remunerated. There is no significant 
(a)

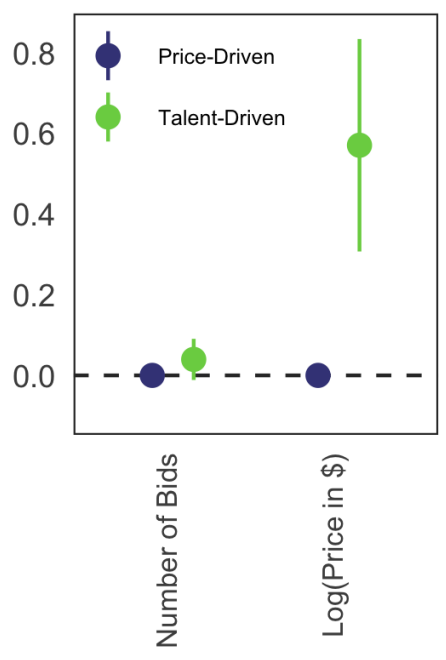

(b)

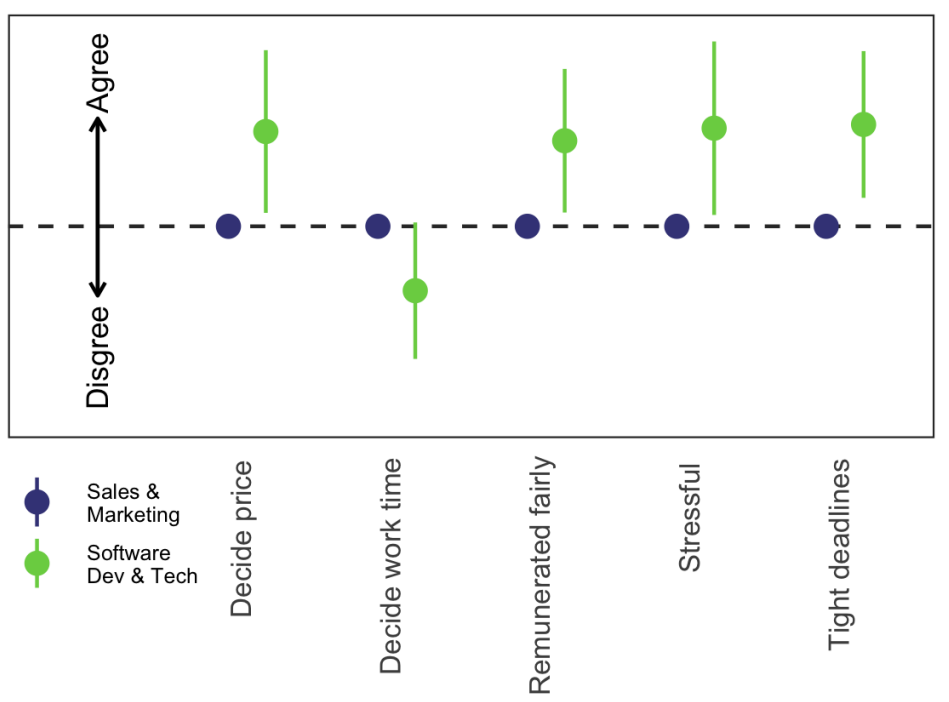

Figure 7: Panel (a) Difference between segments in average competition and remuneration per project: number of bids estimated via Poisson regression (count variable) and $\log _{e}($ Price in $\$$ ) estimated by ordinary least squares regression, both with a dummy variable for segments (ref. price-driven segment). Intercept is omitted as I am interested only in group contrasts and the lines around the point estimate represent the $95 \%$ confidence interval. Source: web-scraped data. Panel (b) Difference between skill groups representing the price-driven segment ("Sales and Marketing") and reputation-driven segment ("Software Development and Technology") in terms of perceived disadvantage. The plot shows estimated mean differences between groups, all weighted by post-stratification weight, and lines represent $95 \%$ confidence intervals. Intercept is omitted as I am interested only in group contrasts. Source: COLLEEM survey data.

difference between the two groups in their perception of being able to decide their working time. Contrary to my expectations, the skill representing the reputation-driven segment is associated with higher levels of stress and incidence of tight deadlines.

Given the presented evidence, there are disadvantages attached to the segmentation, but these mostly concern remuneration of workers. Competition or working time autonomy do not seem to differ between the segments. The reputation-driven segment seems to comprise skills that are prone to higher levels of stress and tighter deadlines than the price-driven segment. The third segmentation hypothesis is hence only partially confirmed and would require further inquiry into the effects of segment membership on the working conditions of freelancers at OLMs.

\section{Discussion and Conclusion}

Over the last decade, digital technologies have been unavoidably integrated into the production process and organisation of labour. Research on OLMs and the platform economy has characterised the emergence of this market as reputation economy (Gandini, 2016), where the algorithmically generated reputation is the primary factor of success (Yoganarasimhan, 2013). 
This is only partially true. Online labour markets are afflicted by segmentation as much as offline labour markets and reputation plays a role only in a fraction of the market. These findings strongly point to the division of the market into segments with distinct dynamics: on the one hand, a market where accumulation of high reputation means potential future security and higher remuneration; and, on the other, a market where workers undercut each other in a race to the bottom, leading to collectively lower pay. Existing theories on precarity and segmentation do not properly address such diversity at OLMs. Unlike the common notion that any platform work is contingent or precarious, the presented evidence shows that online labour markets present yet another level of complexity to labour market segmentation.

Fragmentation of jobs into tasks is the main force that leads to standardization of work into elementary units that can be outsourced to anybody globally (Valenduc \& Vendramin, 2017). Such standardisation challenges traditional dynamics regarding on-the-job training - a crucial source of accumulation of human capital (Lynch, 1991). Employers use online labour markets to outsource the onus of skill formation to individuals, who are expected to become responsible for their education, skills, and professional profile. In effect, workers are expected to become self-investing units of human capital (Brown et al., 2015). Gig workers must adapt their skills and work strategies in order to leverage platforms creatively and productively (Sutherland et al., 2019). Although work online can offer a new pathway to practising skills and enhancing employability (Barnes et al., 2015), not everyone reaps such benefits and only workers who practice skills that are of use outside of the platform economy acquire experiential dividends transferable offline. Low-level repetitive skills do not acquire further dividends from prolonged practice, which can have further socially stratifying effects. The nature of repetitive and unchallenging work may even lead to deskilling as workers do not get opportunities to practice their craft at the edge of their skill to improve (Drahokoupil \& Piasna, 2017). The positive benefit of working at online labour markets is likely to be concentrated in the reputation-driven segment, hence providing another source of differentiation between workers.

Efforts to overcome the boundary from the price-driven to reputation-driven segment can, however, have also negative consequences for the worker. As Leung (2014) shows, erratic behaviour regarding use of skills in online labour markets can lead to diminishing one's market position. On the one hand, some switching between skills can increase candidate's desirability as it is perceived as being multi-talented and signals breadth of one's abilities; on the other, too much switching between skills brings forward risk of being labelled as dilettante and spreading one's skills too thinly. In labour markets, specialisation is theorised to signal greater skill than would be found among generalists who span across many skill-clusters (Ferguson \& Hasan, 2013). Workers at online labour markets, especially from developing countries, will often be forced by their circumstances to undertake projects that are unrelated to their core skill-set just to earn their living, which can backfire against their future ability to get better projects. Precarious workers are forced to move between jobs, because they have no choice - workers who are unable to obtain work in their respective field are forced to jump on any available work, which can further diminish their position as a worker of high ability (Gibbons \& Katz, 1991). A significant difference between offline and online labour markets dwells in the ability of the offline workers to tailor their previous experience to the needs of the employer (potentially omitting employment experience that would decrease their chances of obtaining the new position). Employment history on the platform is however immutable, therefore freelancers lose the power to adapt how they present themselves on the platform (see Leung, 2014). Every interaction is therefore consequential and can influence worker's 
subsequent chances for success.

Online labour market platforms are widely considered among the most disruptive players of the last decade. The sudden rise of online platforms revived the notion of a global labour market and whether it is even achievable (Graham \& Anwar, 2019). Existing research shows that online labour markets, though successful in cutting the costs of offshoring of service work for employers, can perpetuate existing societal inequalities that are observed offline (see Lukac \& Grow, 2020). As mentioned previously, fragmentation, precariousness, insecurity and instability are the permanent traits of the online workforce (Arcidiacono et al., 2019). OLMs operate in a vastly unregulated institutional setting compared to offline markets. Coexistence of offline and online labour markets has been described as "parasitic", because the most precarious workers online rely on financial buffers provided by social mechanisms that are not supported from the digital economy (Schor et al., 2020). As such, more research is required to untangle the embedded and overlapping nature of online and offline labour market to understand the position of individuals who live at the intersection of both.

This paper builds on the theory of labour market segmentation to explore the segregation of the online labour market platforms into segments similar to offline labour markets. In it, I test three hypotheses of a segmented labour market with data from an online labour market platform: existence of structurally delimited segments with different allocation mechanisms, lack of mobility between segments, and distinction of job quality between the segments. Results show evidence of differentiated online labour markets into segments, with relatively low mobility in-between and some job quality differentiation. As a result, exploring the future of work mediated by platforms, researchers should take this additional complexity into account and avoid treating online labour markets as entities that produce uniform experiences for workers. 


\section{References}

Abrahao, B., Parigi, P., Gupta, A., \& Cook, K. S. (2017). Reputation offsets trust judgments based on social biases among Airbnb users. Proceedings of the National Academy of Sciences, 114(37), 9848-9853. https://doi.org/10.1073/pnas.1604234114

Agrawal, A., Horton, J., Lacetera, N., \& Lyons, E. (2015). Digitization and the contract labor market. Economic analysis of the digital economy (pp. 219-256). University of Chicago Press. https://doi.org/10.7208/chicago/9780226206981.003.0008

Ajunwa, I. (2018). Facebook users aren't the reason facebook is in trouble now. the Washington Post. https://www.washingtonpost.com/news/posteverything/wp/2018/03/23/ facebook-users-arent-the-reason-facebook-is-in-trouble-now/

Ajunwa, I., \& Greene, D. (2019). Platforms at work: Automated hiring platforms and other new intermediaries in the organization of work. Work and labor in the digital age (pp. 61-91). Emerald Publishing Limited. https://doi.org/10.1108/s0277-283320190000033005

Anderson, E. (2017). Private government: How employers rule our lives (and why we don't talk about it. Princeton University Press.

Arcidiacono, D., Borghi, P., \& Ciarini, A. (2019). Platform work: From digital promises to labor challenges. https://doi.org/10.1285/I20356609V12I3P611

Autor, D. H. (2001). Wiring the labor market. Journal of Economic Perspectives, 15(1), 2540. https://doi.org/10.1257/jep.15.1.25

Barnes, S.-A., Green, A., \& de Hoyos, M. (2015). Crowdsourcing and work: Individual factors and circumstances influencing employability. New Technology, Work and Employment, 30(1), 16-31. https://doi.org/10.1111/ntwe.12043

Becker, G. (1964). Human Capital: A Theoretical and empirical analysis, with special reference to education. The University of Chicago Press.

Beerepoot, N., \& Lambregts, B. (2014). Competition in online job marketplaces: Towards a global labour market for outsourcing services? Global Networks, 15(2), 236-255. https://doi.org/10.1111/glob.12051

Benson, A., Sojourner, A., \& Umyarov, A. (2019). Can Reputation Discipline the Gig Economy? Experimental Evidence from an Online Labor Market. Management Science. https://doi.org/10.1287/mnsc.2019.3303

Bidwell, M. J. (2013). What Happened to Long-Term Employment? The Role of Worker Power and Environmental Turbulence in Explaining Declines in Worker Tenure. Organization Science, 24 (4), 1061-1082. https://doi.org/10.1287/orsc.1120.0816

Blondel, V. D., Guillaume, J.-L., Lambiotte, R., \& Lefebvre, E. (2008). Fast unfolding of communities in large networks. Journal of Statistical Mechanics: Theory and Experiment, 2008(10), P10008. https://doi.org/10.1088/1742-5468/2008/10/p10008

Bol, T., de Vaan, M., \& van de Rijt, A. (2018). The Matthew effect in science funding. Proceedings of the National Academy of Sciences, 115(19), 4887-4890. https://doi. org/10.1073/pnas.1719557115

Brandes, U., Delling, D., Gaertler, M., Gorke, R., Hoefer, M., Nikoloski, Z., \& Wagner, D. (2008). On modularity clustering. IEEE Transactions on Knowledge and Data Engineering, 20(2), 172-188. https://doi.org/10.1109/tkde.2007.190689

Brown, P., Cheung, S. Y., \& Lauder, H. (2015). Beyond a human capital approach to education and the labour market. New perspectives on industrial policy for a modern 
britain (pp. 206-224). Oxford University Press. https:// doi.org/10.1093/acprof: oso/9780198706205.003.0011

Bunyaratavej, K., Doh, J., Hahn, E. D., Lewin, A. Y., \& Massini, S. (2011). Conceptual issues in services offshoring research: A multidisciplinary review. Group $\&$ Organization Management, 36(1), 70-102. https://doi.org/10.1177/1059601110390996

Bunyaratavej, K., Hahn, E. D., \& Doh, J. P. (2007). International offshoring of services: A parity study. Journal of International Management, 13(1), 7-21. https://doi.org/10. 1016/j.intman.2006.05.002

Cui, R., Li, J., \& Zhang, D. (2019). Reducing Discrimination with Reviews in the Sharing Economy: Evidence from Field Experiments on Airbnb. Management Science. https: //doi.org/10.1287/mnsc.2018.3273

De Stefano, V. (2016). The Rise of the "Just-in-Time Workforce": On-Demand Work, Crowdwork, and Labor Protection in the "Gig Economy". Comparative Labor Law Journal, 37, 471-504.

Dellarocas, C. (2004). Online reputation mechanisms. The practical handbook of internet computing. Chapman; Hall/CRC. https://doi.org/10.1201/9780203507223.ch20

DiPrete, T. A., \& Eirich, G. M. (2006). Cumulative advantage as a mechanism for inequality: A review of theoretical and empirical developments. Annual Review of Sociology, 32(1), 271-297. https://doi.org/10.1146/annurev.soc.32.061604.123127

Doeringer, P., \& Piore, M. J. (1971). Internal labor markets and manpower analysis. M.E. Sharpe.

Doh, J. P. (2005). Offshore outsourcing: Implications for international business and strategic management theory and practice. Journal of Management Studies, 42(3), 695-704.

Doh, J. P., Bunyaratavej, K., \& Hahn, E. D. (2009). Separable but not equal: The location determinants of discrete services offshoring activities. Journal of International Business Studies, 40(6), 926-943.

Dörflinger, N. (2016). Different worlds of work? A study on labour market regulatory institutions and contingent work in Belgium and Germany [Unpublished PhD thesis].

Dossani, R., \& Kenney, M. (2003). "Lift and Shift": Moving the Back Office to India. Information Technologies and International Development, 1(2), 21-37. https://ideas.repec. org/a/tpr/itintd/v1y2003i2p21-37.html

Dossani, R., \& Kenney, M. (2009). Service Provision for the Global Economy: The Evolving Indian Experience. Review of Policy Research, 26(1-2), 77-104. https://doi.org/10. 1111/j.1541-1338.2008.00370.x

Drahokoupil, J., \& Piasna, A. (2017). Work in the platform economy: Beyond lower transaction costs. Intereconomics, 52(6), 335-340. https://doi.org/10.1007/s10272-0170700-9

Emmenegger, P., Häusermann, S., Palier, B., \& Seeleib-Kaiser, M. (2012). The age of dualization: The changing face of inequality in deindustrializing societies. Oxford University Press.

Eurofound. (2017). Aspects of nonstandard employment in Europe. Publications Office of the European Union, Luxembourg.

Eurofound. (2019). Platform work: Maximising the potential while safeguarding standards? Publications Office of the European Union, Luxembourg.

Farrell, D. (2005). Offshoring: Value creation through economic change. Journal of Management Studies, 42(3), 675-683. https://doi.org/10.1111/j.1467-6486.2005.00513.x 
Ferguson, J.-P., \& Hasan, S. (2013). Specialization and career dynamics. Administrative Science Quarterly, 58(2), 233-256. https://doi.org/10.1177/0001839213486759

Fiske, S. T., \& Taylor, S. E. (1991). Social cognition. McGraw-Hill.

Gandini, A. (2016). The reputation economy: Understanding knowledge work in digital society. Palgrave Macmillan.

Gefen, D., \& Carmel, E. (2008). Is the World Really Flat? A Look at Offshoring at an Online Programming Marketplace. MIS Quarterly, 32(2), 367-384.

Gibbons, R., \& Katz, L. F. (1991). Layoffs and lemons. Journal of Labor Economics, 9(4), 351-380. http://www.jstor.org/stable/2535075

Goldman, E. (2011). Regulating reputation. In H. Masum \& M. Tovey (Eds.), The reputation society : How online opinions are reshaping the offline world (pp. 51-62). MIT Press.

Graham, M., \& Anwar, M. A. (2019). The global gig economy: Towards a planetary labour market? First Monday, 24(4). https://doi.org/10.5210/fm.v24i4.9913

Hacker, J. (2019). The great risk shift: The new economic insecurity and the decline of the American dream. Oxford University Press.

Hanley, C. (2014). Putting the bias in skill-biased technological change? a relational perspective on white-collar automation at general electric. American Behavioral Scientist, 58(3), 400-415. https://doi.org/10.1177/0002764213503339

Häuserman, S., \& Schwander, H. (2012). Varieties Of Dualization? Labor Market Segmentation and Insider-Outsider Divides Across Regimes. In P. Emmenegger, S. Häusermann, B. Palier, \& M. Seeleib-Kaiser (Eds.), The Age of Dualization (pp. 27-51). Oxford University Press.

Horton, J. (2010). Online labor markets. SSRN Electronic Journal. https://doi.org/10.2139/ Ssrn. 1689743

Ilsøe, A., Larsen, T. P., \& Bach, E. S. (2021). Multiple jobholding in the digital platform economy: Signs of segmentation. Transfer: European Review of Labour and Research, 102425892199262. https://doi.org/10.1177/1024258921992629

Kalleberg, A. L. (2003). Flexible firms and labor market segmentation. Work and Occupations, 30(2), 154-175. https://doi.org/10.1177/0730888403251683

Kalleberg, A. L. (2011). Good jobs, bad jobs: The rise of polarized and precarious employment systems in the United States, 1970s to 2000s. Russell Sage Foundation.

Kalleberg, A. L. (2012). Job Quality and Precarious Work: Clarifications, Controversies, and Challenges. Work and Occupations, 39(4), 427-448. https://doi.org/10.1177/ 0730888412460533

Kalleberg, A. L., \& Sorensen, A. B. (1979). The sociology of labor markets. Annual Review of Sociology, 5, 351-379. http://www.jstor.org/stable/2945959

Kas, J., Corten, R., \& van de Rijt, A. (2019). The role of reputation systems in digital discrimination. https://doi.org/10.31235/osf.io/85cze

Kässi, O., \& Lehdonvirta, V. (2018). Online labour index: Measuring the online gig economy for policy and research. Technological Forecasting and Social Change, 137, 241-248. https://doi.org/10.1016/j.techfore.2018.07.056

Kokkodis, M., \& Ipeirotis, P. G. (2016). Reputation transferability in online labor markets. Management Science, 62 (6), 1687-1706. https://doi.org/10.1287/mnsc.2015.2217

Lazear, E. P., Shaw, K. L., \& Stanton, C. T. (2018). Who Gets Hired? The Importance of Competition among Applicants. Journal of Labor Economics, 36(S1), S133-S181. https://doi.org/10.1086/694908 
Lehdonvirta, V., Hjorth, I., Graham, M., \& Barnard, H. (2015). Online labor markets and the persistence of personal networks: Evidence from workers in southeast Asia [Presented at ASA 2015 in Oxford, UK].

Lehdonvirta, V., Kässi, O., Hjorth, I., Barnard, H., \& Graham, M. (2018). The global platform economy: A new offshoring institution enabling emerging-economy microproviders. Journal of Management, 45(2), 567-599. https://doi.org/10.1177/0149206318786781

Leung, M. D. (2014). Dilettante or Renaissance Person? How the Order of Job Experiences Affects Hiring in an External Labor Market. American Sociological Review, 79(1), 136-158. https://doi.org/10.1177/0003122413518638

Levy, D. L. (2005). Offshoring in the new global political economy. Journal of Management Studies, 42(3), 685-693. https://doi.org/10.1111/j.1467-6486.2005.00514.x

Lukac, M., Doerflinger, N., \& Pulignano, V. (2019). Developing a cross-national comparative framework for studying labour market segmentation: Measurement equivalence with latent class analysis. Social Indicators Research, 145(1), 233-255. https://doi.org/10. 1007/s11205-019-02101-3

Lukac, M., \& Grow, A. (2020). Reputation systems and recruitment in online labour markets: Insights from agent-based model. Journal of Computational Social Science, Online First. https://doi.org/10.1007/s42001-020-00072-x

Lynch, L. M. (1991). The role of off-the-job vs. on-the-job training for the mobility of women workers. The American Economic Review, 81(2), 151-156. http://www.jstor.org/ stable/2006844

McDonald, S., Damarin, A. K., Lawhorne, J., \& Wilcox, A. (2019). Black holes and purple squirrels: A tale of two online labor markets. Work and labor in the digital age (pp. 93120). Emerald Publishing Limited. https://doi.org/10.1108/s0277-283320190000033006

McLachlan, G. J., \& Peel, D. (2000). Finite mixture models. John Wiley \& Sons, Inc.

McLachlan, G. J., \& Rathnayake, S. (2014). On the number of components in a Gaussian mixture model. Data Mining and Knowledge Discovery, 4(5), 341-355. https://doi. org/10.1002/widm.1135

Merton, R. K. (1968). The Matthew Effect in Science: The reward and communication systems of science are considered. Science, 159(3810), 56-63. https://doi.org/10.1126/science. 159.3810 .56

Newman, M. E. J., \& Girvan, M. (2004). Finding and evaluating community structure in networks. Physical Review E, 69(2). https://doi.org/10.1103/physreve.69.026113

Nylund, K. L., Asparouhov, T., \& Muthén, B. O. (2007). Deciding on the Number of Classes in Latent Class Analysis and Growth Mixture Modeling: A Monte Carlo Simulation Study. Structural Equation Modeling: A Multidisciplinary Journal, 14(4), 535-569. https://doi.org/10.1080/10705510701575396

Osterman, P. (1975). An empirical study of labor market segmentation. ILR Review, 28(4), 508-523. https://doi.org/10.1177/001979397502800402

Pallais, A. (2014). Inefficient hiring in entry-level labor markets. American Economic Review, 104 (11), 3565-3599. https://doi.org/10.1257/aer.104.11.3565

Pelletier, A., \& Thomas, C. (2018). Information in online labour markets. Oxford Review of Economic Policy, 34(3), 376-392. https://doi.org/10.1093/oxrep/gry005

Pesole, A., Urzi Brancati, C., Fernández Macías, E., Biagi, F., \& Vázquez, I. G. (2018). Platform workers in Europe evidence from the COLLEEM survey. European Commission: Joint Research Centre. 
Petrongolo, B., \& Pissarides, C. A. (2001). Looking into the Black Box: A Survey of the Matching Function. Journal of Economic Literature, 39(2), 390-431.

Piore, M. J. (2002). Thirty years later: Internal labor markets, flexibility and the new economy. Journal of Management and Governance, 6(4), 271-279. https://doi.org/10.1023/a: 1021212904674

Polivka, A. E., Cohany, S. R., \& Hipple, S. (2000). Definition, Composition, and Economic Consequences of Nonstandard Workforce. In F. Carré, L. G. M. A. Ferber, \& S. A. Herzenberg (Eds.), Nonstandard work: The nature and challenges of changing employment arrangements. Industrial Relations Research Association, University of Illinois at Urbana-Champaign.

Reich, M., Gordon, D. M., \& Edwards, R. C. (1973). A theory of labor market segmentation. The American Economic Review, 63(2), 359-365. http://www.jstor.org/stable/ 1817097

Rubery, J., Marchington, M., Grimshaw, D., Carroll, M., \& Pass, S. (2009). Employed under different rules: The complexities of working across organizational boundaries. Cambridge Journal of Regions, Economy and Society, 2(3), 413-427. https://doi.org/10. 1093/cjres/rsp017

Schor, J. B., Attwood-Charles, W., Cansoy, M., Ladegaard, I., \& Wengronowitz, R. (2020). Dependence and precarity in the platform economy. Theory and Society, 49(5-6), 833861. https://doi.org/10.1007/s11186-020-09408-y

Snijders, C., \& Matzat, U. (2019). Online reputation systems. In F. Giardini, R. Wittek, A. Diekmann, \& W. Przepiorka (Eds.), The Oxford Handbook of Gossip and Reputation (1st ed., pp. 479-496). Oxford University Press.

Snir, E. M., \& Hitt, L. M. (2003). Costly bidding in online markets for IT services. Management Science, 49(11), 1504-1520. https://doi.org/10.1287/mnsc.49.11.1504.20587

Spreitzer, G. M., Cameron, L., \& Garrett, L. (2017). Alternative work arrangements: Two images of the new world of work. Annual Review of Organizational Psychology and Organizational Behavior, 4(1), 473-499.

Squazzoni, F., \& Gandelli, C. (2012). Saint Matthew strikes again: An agent-based model of peer review and the scientific community structure. Journal of Informetrics, 6(2), 265-275. https://doi.org/10.1016/j.joi.2011.12.005

Srnicek, N. (2017). Platform capitalism. Polity.

Standing, G. (2011). The Precariat: The new dangerous class. Bloomsbury Academic.

Stanton, C. T., \& Thomas, C. (2015). Landing the first job: The value of intermediaries in online hiring. The Review of Economic Studies, 83(2), 810-854. https://doi.org/10. 1093/restud/rdv042

Sutherland, W., Jarrahi, M. H., Dunn, M., \& Nelson, S. B. (2019). Work precarity and gig literacies in online freelancing. Work, Employment and Society, 095001701988651. https://doi.org/10.1177/0950017019886511

Valenduc, G., \& Vendramin, P. (2017). Digitalisation, between disruption and evolution. Transfer: European Review of Labour and Research, 23(2), 121-134. https:// doi . org $/ 10.1177 / 1024258917701379$

Wood, A. J., Graham, M., Lehdonvirta, V., \& Hjorth, I. (2018). Good gig, bad gig: Autonomy and algorithmic control in the global gig economy. Work, Employment and Society, 33(1), 56-75. https://doi.org/10.1177/0950017018785616

Yoganarasimhan, H. (2013). The value of reputation in an online freelance marketplace. Marketing Science, 32(6), 860-891. https://doi.org/10.1287/mksc.2013.0809 
Youngdahl, W., \& Ramaswamy, K. (2007). Offshoring knowledge and service work: A conceptual model and research agenda. Journal of Operations Management, 26 (2), 212-221. https://doi.org/10.1016/j.jom.2007.02.007

\section{Affiliation:}

Martin Lukac

Department of Methodology

London School of Economics and Political Science

E-mail: m.lukac@lse.ac.uk

URL: http://mblukac.github.io

\section{SocArXiv Preprints}

Preprint

10.31235/osf.io/m7ah4 https://osf.io/preprints/socarxiv Submitted: February 19, 2021 Accepted: February 19, 2021 